\title{
ANÁLISE DOS CONTRATOS NA AVICULTURA DE CORTE EM MATO GROSSO SOB A ÓTICA DA NOVA ECONOMIA INSTITUCIONAL (NEI) ${ }^{1}$
}

\author{
Cleiton Franco ${ }^{2}$ \\ Sandra Cristina de Moura Bonjour ${ }^{3}$ \\ Benedito Dias Pereira ${ }^{4}$ \\ Talitha Soyara Zanini ${ }^{5}$
}

\begin{abstract}
Resumo: A produção brasileira de carne de frango em 2010 chegou a 12,230 milhões de toneladas, em um crescimento de $11,38 \%$, impulsionada pela expansão do consumo e aumento das exportações. O Mato Grosso é o $7^{\circ}$ maior produtor nacional em termos de abate, e os números de produção crescem a cada ano, considerando a produção de grãos de soja e milho e a potencialidade de plantio de novas áreas, tornando a avicultura a vedete deste novo cenário. O presente artigo tem o objetivo de analisar contratos da avicultura de corte em Mato Grosso sob a ótica da Nova Economia Institucional. O referencial teórico adotado fornece os conceitos de custos de transação e estruturas de governança. Os dados foram provenientes de contratos referentes à integração da avicultura de corte no período de 2008 e 2009 , do ponto de vista das três empresas situadas no Estado de Mato Grosso, região Centro-Oeste do Brasil. Os resultados apontam que os contratos de integração têm sido importante instrumento, tanto para as empresas integradoras, que contam com a produção constante e em padrões previamente especificados visando a atender o mercado interno e externo, quanto aos produtores rurais, que têm na avicultura, uma atividade que lhes garante venda e recebimento por parte da indústria. Os contratos de integração podem ser considerados de média especificidade de ativos, com transação frequente e reduzida incerteza.
\end{abstract}

Palavras-chaves: Nova Economia Institucional, Contratos, atributos das Transações, avicultura.

\footnotetext{
Recebido em: 04/07/2011.

Aceito em: 04/11/2011.

2 Professor Mestre Efetivo do Departamento de Ciências Contábeis, UNEMAT - Universidade do Estado de Mato Grosso, campus de Tangará da Serra. Coordenador do Núcleo de Pesquisa e Extensão Econômico Social e Contábil. E-mail: cleitonfranco@unemat.br

3 Professora Doutora em Economia - UFMT - Programa Agronegócio e Desenvolvimento Regional - Faculdade de Economia. E-mail: sbonjour@gmail.com

4 Professor Doutor em Economia - UFMT - Programa Agronegócio e Desenvolvimento Regional - Faculdade de Economia. E-mail: bdp@terra.com.br

5 Professora Bióloga - Participante do Núcleo de Pesquisa e extensão Econômico Social e Contábil (NEPEC) - UNEMAT - Universidade do Estado de Mato Grosso, campus de Tangará da Serra. E-mail: talisoyara@hotmail.com
} 


\begin{abstract}
The Brazilian production of poultry meat in 2010 reached 12.230 million tons, a growth of $11.38 \%$, driven by increased consumption and increased exports. Mato Grosso is the 7th. Major national producer in terms of slaughter and production numbers are growing every year, considering the production of soybeans and corn and the possibility of planting new areas, making poultry the star of this new scenario. This article aims to examine contracts of broiler farms in Mato Grosso from the perspective of New Institutional Economics. The theoretical reference provides the concepts of transaction costs and governance structures. The data were derived from contracts related to the integration of poultry production in the period of 2008 and 2009, from the point of view of three companies located in the State of Mato Grosso, Central-West region of Brazil. The results show that the integration contracts have been an important tool for both the integrated companies, which rely on constant production and prespecified standards to meet the domestic and foreign markets, and to farmers who have in the poultry industry, an activity which gives them guaranteed sales and receipt by the industry. The integration contracts can be considered medium asset specificity, transaction-frequent and reduced uncertainty.
\end{abstract}

Keywords: New Institucional Economy, Contracts, Attributes of the Transactions, poultry keeping.

\title{
1. Introdução
}

No Brasil, a produção de carne de frango atingiu em 2010, cerca de 12 milhões de toneladas, apresentando crescimento de $65 \%$ no período de 2002 a 2010, e a projeção é chegar aos 13 milhões ao final de 2011 (MAPA, 2011). O consumo per capita, tendo como um dos fatores principais a redução do preço no varejo, evoluiu $47 \%$ nos últimos 10 anos, chegando a $44 \mathrm{~kg} / \mathrm{hab} / \mathrm{ano}$, índice superior ao das carnes suína $(14,6)$ e bovina $(32,5)$, e o mesmo dos Estados Unidos. Nas exportações, a carne de frango é o quinto maior produto nacional, liderando o mercado mundial com $40 \%$ das exportações totais. As exportações representam 3 milhões de toneladas ou $28 \%$ de toda produção nacional. Os resultados são fruto da capacidade técnica e tecnológica na produção frangos e matrizes. As altas sanidades na produção avícola presentes em toda a cadeia produtiva aliadas ao aumento da conversão alimentar melhorando a produtividade garantem à avicultura um futuro promissor como atividade mais relevante para o agronegócio brasileiro (NETO, 2011). 
Cleiton Franco, Sandra Cristina de Moura Bonjour, Benedito Dias Pereira

\& Talitha Soyara Zanini

O agronegócio mato-grossense é constantemente considerado elemento fundamental para a economia do estado, englobando os mais diversos produtos como grãos (soja, milho, algodão, entre outros), carnes e tantos outros produzidos nas diversas regiões, interferindo diretamente no desenvolvimento econômico e regional.

O Mato Grosso é o $7^{\circ}$ maior produtor nacional de aves de corte, responsável por 1,7 milhões de alojamentos de matrizes e 130.883 mil cabeças na produção de pintinhos, representando em termos de evolução mais de $100 \%$ na análise de dados dos últimos dez anos (ANUALPEC, 2011). Assim, é importante melhorar o processo produtivo (criação de aves para corte), bem como a industrialização, tornando a atividade competitiva, tanto nacional quanto internacionalmente, aumentando lucros e reduzindo custos para produtores e empresas. Uma forma de aperfeiçoar este processo produtivo é a padronização da produção de frangos, atendendo aos padrões exigidos pelos clientes.

A adoção desses contratos de integração leva ao entendimento de que há integração vertical por parte da indústria processadora ou contratos de longo prazo para determinação da estrutura de governança adequada? Defende-se a ideia de que, segundo a teoria dos custos de transação, a integração vertical ou complexos contratos de longo prazo seriam usados para apoiar a negociação eficiente entre produtor avícola e agroindústria.

A modalidade de negociação adotada pelas indústrias ocorre na forma de fornecimento das técnicas, dos processos, do melhoramento genético, das rações e dos insumos, em contrapartida os produtores de frango assumem a responsabilidade de construção das instalações, da aquisição dos equipamentos, da mão de obra e dos cuidados dispensados aos frangos. Nesse sentido há um esforço para identificar a estrutura de governança adotada, fazendo comparações entre diferentes tipos de plantas de abate e processamento de frangos em Mato Grosso por meio da análise dos contratos de fornecimento de insumos e da efetiva adoção da teoria dos custos de transação. 
Este artigo tem o objetivo de analisar os contratos de produção de frangos de corte, adotados entre empresas localizadas em Mato Grosso e os produtores rurais integrados. Serão evidenciadas as particularidades dos contratos de cada empresa, de acordo com o arcabouço teórico da Nova Economia Institucional (NEI).

\section{Referencial teórico}

\subsection{Nova Economia Institucional (NEI)}

O marco inicial da Nova Economia Institucional (NEI) foi a publicação do artigo The nature of the firm, de Ronald Coase, em 1937, no qual a principal questão levantada se referia aos custos de transação, deixandose de analisar a firma como uma função de produção, passando a ser uma organização de coordenação de agentes econômicos e um nexo de contratos.

Observou-se que as transações do sistema econômico não eram isentas de custos, e que basicamente duas eram as formas de custos: os que se referiam à coleta de informações e os referentes à negociação e estabelecimento de contratos. Estes custos eram gerados por todos os agentes econômicos, bancos, advogados, corretores e não apenas àqueles ligados à produção (COASE, 1937).

O enfoque da análise de Coase destaca as formas de coordenação mercado e firma, não negando a importância das formas intermediárias de coordenação. Mercado e firma competem por terem a função comum de coordenar a atividade econômica, portanto, coexistem. Surgiu então a necessidade de distinguir os custos de produção dos outros custos, vinculados à tecnologia e ao relacionamento dos agentes, que receberam a designação de Custos de Transação, os quais podem ser definidos em quatro níveis: o primeiro nível relaciona-se com os custos de construção e negociação dos contratos; o segundo envolve os custos por medir e monitorar os direitos de propriedade existentes no contrato. Esse nível 
Cleiton Franco, Sandra Cristina de Moura Bonjour, Benedito Dias Pereira

\& Talitha Soyara Zanini

incorpora os custos de observação dos contratos ao longo do tempo para seu desempenho e atende às expectativas das partes que fizeram a transação. O terceiro nível engloba os custos de manter e fazer executar os contratos internos e externos da firma. O quarto e último nível relaciona-se com os custos de adaptação que os agentes sofrem com as mudanças ambientais (FARINA, 1999; WILLIAMSON, 2002).

Os custos de transação, no entanto, não são facilmente mensuráveis, por estarem relacionados principalmente com as atitudes e/ou comportamento das partes envolvidas nas negociações, com seus atributos comportamentais (racionalidade limitada e oportunismo), que podem ocorrer tanto no pré como pós-contrato.

Williamson (1979) evidenciou o termo NEI e empenhou-se em atribuir dimensões às transações, fornecendo elementos que permitissem a identificação de ação oportunista por parte dos agentes envolvidos. Dependendo da transação e da intensidade dos atributos, os custos de transação poderiam ser inferidos. Williamson descreve o ambiente microanalítico das propriedades da estrutura de governança das transações de forma que os custos de transação são relevantes para esta teoria.

North (1994), ao discutir o ambiente macroanalítico, onde são desenvolvidas as transações, cita quatro variáveis que influenciam diretamente nos custos de transação:

- O custo da quantificação dos atributos do bem ou serviço: avalia não apenas as dimensões físicas, mas também os direitos de propriedade envolvidos na transação; um exemplo simples é do automóvel, que muitas pessoas compram por terem determinada cor, performance, potência, mas qualquer que seja a escolha a finalidade é de transportar;

- Tamanho do mercado: se as transações são pessoais (com parentes, amigos) ou impessoais (desconhecidos), neste caso, não há nada que impeça as pessoas de levar vantagem sobre as outras; 
- Cumprimento das obrigações assumidas: a evolução do sistema jurídico, fiscalizador e imparcial, fundamental para o desenvolvimento de sistema contratual complexo e eficiente; e

- Atitudes ideológicas e percepções: como as pessoas veem as regras do jogo (instituições) e de que forma agem frente às transações e regras.

A NEI, portanto, é uma extensão da Organização Industrial, inserindo o ambiente institucional e as variáveis transacionais, caracterizando a organização de firmas e de mercados. Procura ainda identificar qual a melhor forma de organização das transações econômicas com a melhor alocação de recursos (FARINA, 1999).

Existem quatro pressupostos fundamentais que precisam ser considerados ao analisar as organizações sob a ótica da NEI:

- A existência de custos na utilização do sistema de preços, tanto se as negociações forem efetuadas via contratos, quanto se forem realizadas internamente na firma;

- As transações acontecem em um ambiente institucional estruturado, as instituições são importantes ao influir nos custos de transação, e o ambiente institucional afeta o processo de transferência dos direitos de propriedade;

- O oportunismo dos agentes é outro pressuposto importante, refere-se ao comportamento das pessoas que agem de forma a beneficiar a si mesmas; o oportunismo pode ocorrer antes do contrato (ex-ante), chamado também de seleção adversa, ou após o contrato (ex-post), denominado risco moral; ambos ocorrem por assimetria de informação; e

- A racionalidade limitada relaciona-se ao comportamento dos agentes que não conseguem desenvolver de forma plena sua capacidade cognitiva, agem de forma racional, mas limitadamente. 
Cleiton Franco, Sandra Cristina de Moura Bonjour, Benedito Dias Pereira \& Talitha Soyara Zanini

Os custos de transação ocorrem porque os agentes econômicos possuem racionalidade limitada e são oportunistas (chamados pressupostos comportamentais), ademais existem as incertezas ambientais, tudo isso torna os contratos sempre incompletos (WILLIAMSON, 1979, 1981, 1985, 2002).

A racionalidade limitada, citada por Williamson $(1979,1981,1985)$, relaciona-se ao fato de os agentes atuarem de forma racional, mas limitadamente, com a intenção de conseguir maiores benefícios ou lucros para sua empresa. Porém, a obtenção de informações e de processamento destas empresas é limitada e custosa. Devido a esta impossibilidade de previsão de todos os eventos e possibilidades futuras, os contratos serão sempre incompletos.

O oportunismo refere-se à ação dos indivíduos em agir aeticamente, visando a obter benefício próprio, e pode ocorrer de duas formas: exante ou ex-post.

O oportunismo ex-ante (antes da transação), nominado também como seleção adversa, ocorre quando o vendedor tenta convencer o comprador de que o produto oferecido é de qualidade. Porém, tanto o vendedor quanto o comprador podem possuir informações privilegiadas do produto, tornando a negociação injusta para uma das partes. Um exemplo bastante utilizado é o de mercado de automóveis usados: o vendedor geralmente possui informações do veículo (um acidente no passado, por exemplo) que não repassa ao comprador.

O oportunismo ex-post (ou moral hazard) ocorre quando um dos agentes possui uma informação privada e pode tirar proveito após a assinatura do contrato, prejudicando a contraparte, podendo ocorrer por informação ou por ação oculta. Exemplificando: seguro de automóvel, o segurado possui a informação de que ele (segurado) age de forma perigosa ao volante, mas não relata à seguradora com a intenção de obter vantagens no valor da parcela do seguro. 
Estes pressupostos devem ser considerados ao se realizar uma transação. Tais características comportamentais passam a responder porque exante os contratos podem não cobrir perfeitamente todas as lacunas regidas em uma transação, visto que o poder de previsão e o cálculo das pessoas não atendem de forma plena e a sua conduta não pode ser considerada confiável (WILLIAMSON, 1981).

\subsection{Atributos das transações}

Além dos pressupostos comportamentais, existem ainda os atributos das transações, que são a frequência, a incerteza e a especificidade dos ativos.

A frequência relaciona-se com a repetição e a intensidade com que a transação ocorre no tempo. Refere-se a dois aspectos importantes nas transações: a redução de custos de monitoramento (porque a relação sempre se realiza) e a construção de reputação dos agentes envolvidos. Como a transação tende a ter continuidade, a ação oportunista é desestimulada sob pena de rompimento da relação (FARINA et al., 1997; WILLIAMSON, 1985).

O atributo incerteza relaciona-se ao desconhecimento dos eventos futuros devido à informação assimétrica e incompleta e aos problemas inerentes aos ambientes e a suas complexidades em que os agentes atuam.

A especificidade dos ativos refere-se aos ativos que não podem ser reempregados em outra atividade, a não ser que haja perda de valor, ocorrendo os custos irrecuperáveis (FARINA et al., 1997; WILLIANSOM, 1985). Esta dimensão das transações pode ser subdividida em:

- Especificidade locacional: relacionada à localização das empresas ou firmas, os aviários e agroindústrias em Mato Grosso, por exemplo; 
Cleiton Franco, Sandra Cristina de Moura Bonjour, Benedito Dias Pereira

\& Talitha Soyara Zanini

- Especificidade física: relacionada às características do produto, não pode ser utilizado em outra função, por exemplo, matéria-prima com características específicas com relação à pureza, textura e composição química ou equipamentos para produção de determinado produto;

- Especificidade de ativos humanos: refere-se ao capital humano empregado na atividade, como mão de obra especializada;

- Especificidade de ativos dedicados: ocorre apenas de forma bilateral, uma firma produz um artigo específico para determinada empresa, e o investimento realizado nesta produção não pode ser reempregado em outras;

- Especificidade de marca: refere-se ao capital de determinada empresa, relevante especialmente no caso de franquias; e

- Especificidade temporal: significativo nos produtos do agronegócio por serem perecíveis e dependentes de curto tempo para processamento sob pena de perda da matéria-prima.

Estas dimensões (incerteza, frequência e especificidade dos ativos) são importantes para a caracterização das transações e seus respectivos custos, visando à sua minimização com a utilização de estruturas de governança que auxiliem neste processo.

\subsection{Contratos}

O contrato pode ser definido sob a ótica da economia das organizações como "uma maneira de coordenar as transações provendo incentivos para os agentes atuarem de maneira coordenada na produção, o que permite um planejamento de longo prazo e, em especial, permitindo que agentes independentes tenham incentivos para se engajar em esforços conjuntos de produção" (ZYLBERSZTAJN ; SZTAJN, 2005). 
Com esta ferramenta, os agentes econômicos transacionam, seja para trocar mercadorias, serviços, gerando renda, consumo e produção.

Os contratos possuem custos relacionados à sua construção, implementação, monitoramento e solução de disputas advindas de não cumprimento do referido contrato. As instituições e organizações são estruturadas para atuar com estas disputas, desenvolvendo ainda tribunais informais e de justiça (JOSKOW, 1985; ZYLBERSZTAJN ; SZTAJN, 2005).

Segundo Joskow (1985) e Fiani (2002), podem-se destacar quatro tipos de contratos:

- Contratos que caracterizam no presente certo desempenho no futuro: não é flexível, indicado apenas para transações simples, em que incerteza e complexidade não estejam presentes;

- Contratos que especificam no presente determinado desempenho futuro, com cláusulas condicionais: indicado quando há interesse em manter um vínculo entre vendedor e comprador, devido aos ativos possuírem alta especificidade; quanto maior a complexidade da transação, torna-se mais difícil elaborar este contrato, a racionalidade limitada impede a antecipação de todas as circunstâncias futuras;

- Contratos de curta duração, apenas quando há necessidade de realizar a transação: as ofertas são feitas em mercado spot (à vista), cada comprador adquire o que deseja e quando lhe convém, o objeto da transação deve ser homogêneo, não importando quem seja o vendedor ou o comprador; e

- Contratos estabelecidos hoje dando direito de selecionar futuramente uma performance específica em um conjunto de performances estipulado anteriormente: chamado ainda de relação de autoridade, não é necessário antecipar todas as circunstâncias futuras nem recontratar sucessivamente, este contrato se refere principalmente aos contratos de trabalho de longa duração. 
De acordo com Williamson (1979), os contratos são classificados em clássicos, neoclássicos e relacionais. Os contratos clássicos relacionamse aos mercados em competição perfeita, as transações ocorrendo em período definido, com transferência de informações entre as partes, os ajustes ocorrem via mercado, as dimensões são plenamente definidas, ou seja, o contrato clássico é apenas um referencial teórico, pois os contratos são sempre incompletos e de correção continuada.

Os contratos neoclássicos são utilizados quando as transações tendem a se estender no longo prazo, e a variável incerteza é relevante. Não há como prever todas as formas de contingência que podem ocorrer ao longo do tempo em que for estabelecido o contrato, tornando necessárias constantes adaptações no momento em que as contingências forem aparecendo, devendo ser negociadas uma a uma pelas partes. A presença de uma terceira parte é necessária para resolver disputas e avaliar o desempenho estipulado pelo contrato no momento posterior à sua assinatura. Essa disputa geralmente é tratada em uma corte judicial.

Os contratos relacionais são a alternativa contratual quando a duração e a complexidade dos contratos são elevadas. As transações caracterizadas por esse tipo de contrato são de muito longo prazo. Desta forma, os contratos são eminentemente incompletos, e as estruturas de governança caminham no sentido da hierarquia, internalizando as transações na empresa.

Joskow (1985), ao estudar a relação de fornecimento de carvão por meio de contratos, evidenciou tais tipicidades, denotando a necessidade de verificação quanto à estrutura de governança a ser adotada, seja por meio de estabelecimento de contratos de longo prazo, seja por integração vertical.

\subsection{Contratos na avicultura de corte sob a ótica de Custos de Transação}

A partir da visão de Coase (1937), foi aberta a possibilidade do estudo de contratos, sejam eles formais ou informais, amparados por leis no primeiro 
caso e por salvaguardas, no segundo. Passou-se então a considerar a firma como um nexo de contratos cuja estrutura - forma de governança - variava conforme as variáveis pudessem ser analisadas, pautadas por regras institucionais. Na agricultura são vários os exemplos de utilização de arranjos contratuais, seja para aquisição de sementes, financiamento da produção, de troca de insumos ou de contratos de futuros para venda programada. De acordo com Zylbersztajn (2005), o departamento de agricultura dos Estados Unidos (USDA) apresentou estudo indicando que a adoção de contratos é mais frequente nos produtores que possuem grau de escala maior, e procura identificar quais as razões que levam os produtores a preferir contratos ao invés de comercializar via mercados, destacando a redução de riscos e a economia de custos de transação como as mais relevantes.

Tabela 1 - Evolução percentual da produção sob contratos em commodities, por ano, na agricultura Norte Americana.

\begin{tabular}{l|c|c|c|c|c}
\hline \multicolumn{1}{c|}{ Produto } & $1991-93$ & $1994-95$ & $1996-97$ & $1998-00$ & 2001 \\
\hline Açúcar & 91,10 & 83,70 & 75,10 & 89,00 & 95,50 \\
Arroz & 19,70 & 25,20 & 25,80 & 30,50 & 38,50 \\
Algodão & 30,40 & 44,50 & 33,80 & 42,90 & 51,70 \\
Frutas & n.a. & 64,20 & 56,80 & 65,40 & 59,00 \\
Bovinos & n.a. & 19,00 & 17,00 & 24,30 & 20,90 \\
Suínos & n.a. & 31,10 & 34,20 & 55,10 & 60,60 \\
Aves & 88,70 & 84,60 & 84,00 & 88,80 & 88,10 \\
\hline
\end{tabular}

Fonte: MacDonald et al. (2004); Zylbersztajn (2005)

A Tabela 1 indica o percentual de contratos observados em produtos escolhidos na agricultura norte-americana no período entre 1991 a 2001. Pode-se perceber que os contratos que envolvem a produção de aves tendem a permanecer num alto patamar contratual por razões de integração da avicultura. No Brasil, ainda de acordo com Zylbersztajn (2005), a avicultura segue a mesma tendência encontrada nos EUA. O 
Cleiton Franco, Sandra Cristina de Moura Bonjour, Benedito Dias Pereira \& Talitha Soyara Zanini

trabalho de Nogueira e Zylbersztajn (2003) mostra a adoção de contratos na indústria avícola brasileira, evidenciando a presente distinção na adoção entre estados no País. Estatísticas indicam que 59,5\% da produção direcionada à exportação provém de empresas integradas (ABEF, 2010). O número é subestimativa, pois no sul do país os contratos entre produtores e empresas integradoras chegam próximos dos $100 \%$, mantendo a mesma tendência em Mato Grosso, sendo menor no Estado de São Paulo.

\subsubsection{Desenvolvimento dos contratos de produção}

Na busca da maximização do lucro, a empresa agroindustrial desenvolve estratégias que possibilitam externalizar seus custos e internalizar seus rendimentos, ou de outra forma, otimizar o lucro sem a perda de posição no mercado ou redução no ciclo de vida. A política de suprimento das agroindústrias leva à adoção de contratos de produção, que podem ser de integração, semi-integração ou fornecimento. Nesses contratos de integração, insumos e tecnologia são fornecidos pela agroindústria, ficando a cargo do produtor a mão de obra e os investimentos em instalações e equipamentos. Nos de semi-integração, há o fornecimento de parte dos insumos pelo produtor, bem como de instalações e equipamentos e, nos contratos de fornecimento, há apenas um compromisso de compra, não implicando fornecimento de insumos (ALTMANN, 1997).

Os meios de produção fornecidos não são adquiridos pelo produtor integrado, o que se tem na verdade é um contrato de trabalho em que o produtor fornece os equipamentos e a mão de obra, assumindo os riscos da produção sem necessariamente participar dos lucros. A razão para o fornecimento dos meios de produção pode ser explicada, parcialmente, pela teoria de crescimentos das firmas. A agroindústria tem interesse em que os custos de produção ao longo da cadeia sejam os mais baixos possíveis. Através da eficácia das rações para a redução da conversão alimentar, da automação das operações, obtêm-se o aumento da produção, a melhoria da qualidade e a redução do tempo de trabalho. A introdução 
de novas tecnologias diminuirá os custos de produção pela redução dos custos de mão de obra, reduzindo também os custos de transação (ALTMANN, 1997; WILLIAMSON, 2002).

De acordo com o proposto por Williamson (2002) e Coase (1937), é interessante a conclusão a respeito da abordagem da decisão de "fazer ou comprar”. A empresa acaba sustentando a atividade de criação por meio de contratos visando à redução de custos e como se trata de oferta única, evita-se assim a necessidade de consulta ao mercado sobre preços. Por meio da adoção de fórmula de remuneração ao integrado, transferemse as perdas de excesso de peso dos lotes de frangos e cobra-se o custo da ração consumida em função da manutenção do peso.

A pesquisa científica e a difusão de resultados nas unidades de produção integrada possibilitaram às agroindústrias coordenar a atividade de produção a montante e a jusante. Para que a atividade de produção seja desenvolvida, as agroindústrias podem intervir de forma direta ou indireta no seu financiamento por intermédio de instituições financeiras, através de acordos e limitar sua intervenção à orientação ao produtor quanto à burocracia e ao aval da operação (ALTMANN, 1997). Em Mato Grosso, as agroindústrias orientam seus integrados a procurar a rede bancária, normalmente o Banco do Brasil, e através de aval, conseguir os recursos para o desenvolvimento da atividade, ficando a empresa com a obrigação de aquisição de toda a produção gerada pelo produtor. A agroindústria ainda consegue desenvolver a coordenação pelo fornecimento de serviços suplementares, como transporte da produção, ração e assistência técnica. Os contratos de integração possibilitam ainda a redução das imobilizações financeiras, que seriam necessárias caso a empresa optasse por se integrar verticalmente. Dessa forma, estes investimentos são transferidos aos produtores, possibilitando a valorização do capital e certo grau de autonomia na busca de mercados alternativos ou na venda do empreendimento. 


\section{Métodos e procedimentos}

\subsection{Modelo analítico}

A fim de se proceder à comparação entre as diferentes formas organizacionais, Williamson (1985) define funções de custos de governança. As diferentes formas apresentam como parâmetros a especificidade de ativos e um vetor de parâmetros de deslocamento das funções. Nesse vetor, Williamson inclui dimensões restantes, tais como incerteza, elementos do ambiente institucional e garantia de direitos de propriedade. A especificidade de ativos $(\mathrm{k})$, necessária para identificar a representatividade na transação, é representada por três níveis:

$\mathrm{K}=0$, para ativos reutilizáveis;

$\mathrm{K}=\infty$, para ativos altamente específicos; e

$\mathrm{K}=\mathrm{m}$, para ativos intermediários.

Enquanto a frequência das transações, fundamental para identificar a quantidade de transações realizadas num intervalo de tempo, também é representada por três níveis:

$\mathrm{F}=1$, para transações realizadas apenas uma vez;

$\mathrm{F}=0$, para transações ocasionais; e

$\mathrm{F}=\mathrm{r}$, para transações recorrentes.

O fator incerteza (risco) é analisado em função das alianças estratégicas adotadas, estabelecidas na relação de confiança entre produtor e agroindústria. 
A combinação da especificidade de ativos e a frequência, essenciais para determinar a espécie de estruturas de governança, a serem observadas:

a) Para $\mathrm{f}=1$ e $\mathrm{k}=0$, é determinada a estrutura de governança via mercado ou de contratos clássicos. b) Para $\mathrm{f}=\mathrm{r}$ e $\mathrm{k}=\mathrm{m}$, é determinada a estrutura de governança hierárquica, através de contratos relacionais. c) Para $\mathrm{f}=0$ e $\mathrm{k}=\mathrm{m}$, é determinada a estrutura de governança híbrida ou através de contratos neoclássicos. d) Quando $\mathrm{k}=\infty$, a elevação de especificidade de ativos determina a internalização da transação.

\subsection{Procedimentos metodológicos}

Adotou-se o método denominado rapid appraisal (método de pesquisa rápida), que busca tornar possível a captação de informações necessárias à realização de investigação de projeto através de entrevistas com agentes-chave na cadeia produtiva, tais como associações, sindicatos, diretores de empresas, instituições, entre outros. Este método tem se mostrado bastante útil quando utilizado na análise de cadeia produtiva, principalmente quando os recursos e tempo são fatores escassos, impedindo a realização de avaliações formais. Tem sido bastante utilizado em análises de sistemas agroalimentares quando as restrições de tempo e recursos financeiros impedem a realização de avaliações baseadas em métodos convencionais de pesquisa amostral, ou quando o interesse está em obter conhecimento amplo sobre os componentes do sistema em estudo (USAID, 1996).

\subsection{Dados e procedimentos empíricos}

Os dados primários foram oriundos de questionários aplicados aos agenteschave, selecionados com base em critérios utilizados pela metodologia Rapid Appraisal, que determina que os agentes sejam escolhidos com base no conhecimento que possuem sobre a região e a cadeia, 
representados nesse trabalho por produtores, fornecedores, sindicatos, proprietários/diretores de indústria de abate e processamento e instituições reguladoras do setor no período compreendido de setembro a dezembro de 2008 .

Os dados quantitativos e qualitativos foram levantados com base na aplicação dos questionários semiestruturados a produtores integrados, bem como seus representantes nos sindicatos da categoria, buscando a captação de informações junto a produtores integrados agentes-chave inseridos no mercado formal, com base nos aspectos de dados referentes a preço, local de entrega, formas de negociação, regularidade de entrega, regularidade e forma de pagamento, exigências mínimas de compradores e cancelamento de acordos. Dessa forma, foi possível compreender as estruturas de governança e as transações entre produtor (integrado) e indústria de abate e processamento (integrador).

Dado o foco do trabalho, foram utilizadas, principalmente, informações referentes a transações entre produtor integrado e empresas integradoras localizadas nos municípios que pertencem à delimitação do espaço de análise, neste caso, os seguintes: Campo Verde, Tangará da Serra, Lucas do Rio Verde, Nova Mutum, Sorriso e Várzea Grande. As empresas analisadas estão inseridas no Sistema de Inspeção Federal (SIF) do Ministério da Agricultura. Para a compreensão do ambiente institucional, foram entrevistados instituições no período de janeiro e fevereiro de 2009 e agentes-chave pertencentes à cadeia produtiva, com relação à atuação de aspectos de comercialização interna e externa, legislação sanitária, tributação e políticas públicas, bem como à sinergia com a cadeia produtiva de grãos, buscando o desenvolvimento no Estado. 


\section{Discussão dos resultados}

\subsection{Transações e determinação das estruturas de governança}

Insumos e produção - De forma geral, verifica-se a ocorrência de transações via mercado juntamente com modalidades contratuais. O fornecimento de linhagens é feito pela transação via mercado spot, normalmente através de fornecedores situados fora do país $(\mathrm{f}=0)$. As vacinas e medicamentos são adquiridos também pelo mercado spot e fornecidos aos produtores integrados com base no contrato de integração $(\mathrm{f}=0)$. Da mesma forma, são contratados médicos veterinários (funcionários) como prestadores de serviço à empresa para garantir a assistência técnica aos produtores integrados para o desenvolvimento da atividade, coleta de amostras, geração de relatórios e verificação de contaminação por doenças como New Castle, entre outras, e que são informadas à empresa integradora, garantindo assim a simetria de informação para a indústria integradora $(\mathrm{f}=\mathrm{r})$. $\mathrm{O}$ fornecimento de rações também é garantido pela empresa integradora através de contrato com produtores em sistema de quase-integração $(\mathrm{f}=\mathrm{r})$.

Grãos e frigoríficos - A indústria de aves necessita exercer um controle preciso sobre a aquisição do milho por parte das empresas de rações. No caso das aves, a presença de microtoxinas, desenvolvidas no processo de armazenagem de milho, pode gerar problemas para a produção. Em outras palavras, há um problema informacional relevante na transação entre indústria de rações e a produção de aves, sendo necessária a aquisição de ração em que se assegure qualidade. Como consequência, cria-se uma relação de dependência mútua, baseada no controle que a indústria de aves necessita ter sobre a oferta de insumos, o que caracteriza os ativos envolvidos como específicos à transação. A relação entre a indústria de rações e a de aves também é marcada por ativos locacionalmente específicos, em decorrência do elevado custo do frete e da necessidade de sintonia fina entre a fábrica de rações e as granjas. Nesse ponto, revela-se outro importante atributo dessa transação: a 
elevada frequência com que ela ocorre (FARINA ; ZYLBERSTAJN, 1998).

Devido às empresas de abate de frangos serem as principais demandantes de rações e por possuírem contratos de integração com produtores (avicultores), elas acabam por desenvolver estratégias que visem a garantir a oferta de ração e a armazenagem deste insumo. Desta forma, as empresas de abate e processamento de frango procuram produzir sua própria ração, de tal forma que parte substancial da ração não chega ao mercado, sendo diretamente transferida entre unidades de negócio da mesma empresa. A estrutura de governança que predomina nesta situação é a integração vertical, pois a fábrica acaba sendo incorporada à indústria de abate e processamento de frangos, tornando-se um ativo específico, pois visa a suprir a demanda dos contratos de integração. Em Mato Grosso, a aquisição de grãos, neste caso soja (farelo) e milho, é realizada por empresas integradoras que acabam por comprá-los no mercado spot através de leilões da Companhia Nacional de Abastecimento (CONAB), instituição vinculada ao Ministério da Agricultura, que visa a contribuir para o fornecimento de grãos e garantia de preços mínimos aos produtores ou então diretamente com produtores situados nos municípios matogrossenses dentro do raio de ação da empresa.

Produção e frigoríficos - A transação com matrizeiros e incubatórios visa ao fornecimento de pintinhos com 1 dia de vida ao integrado para o processo de criação $(\mathrm{f}=\mathrm{r})$. Ambos os sistemas obedecem à estrutura de governança de integração vertical com a empresa integradora a fim de garantir o suprimento regular de matéria-prima. Na fase considerada de pré-transação, são exigidos garantias hipotecárias (terras livres de hipotecas), licenciamento ambiental único (LAU), adequações de redes de energia elétrica, projeto de construção civil dos aviários e carta consulta, com aval da empresa integradora, encaminhada ao Banco do Brasil, analisada pela Câmara pertencente à Secretaria de Desenvolvimento Rural (SEDER) para aquisição de recursos que darão início ao projeto de construção dos aviários ( $\mathrm{f}=1)$. 
Depois de realizada a concessão de autorização, os recursos são liberados em conta corrente do proprietário que se dirige à empresa para a assinatura do contrato de integração. Desta forma, serão construídos os aviários, seguindo as metragens padrão determinadas pela empresa, com caixas d'água e silos para armazenagem de ração. Como parte da exigência para a manutenção contratual, faz-se necessária a adequação às exigências de biossegurança, como construção de portões sanitários, banheiros para higienização, utilização de roupas para visitas de assistência técnica, retirada de frangos, alojamentos de pintinhos e manutenção dos aviários $(\mathrm{f}=1)$.

A partir desse momento, o produto passa a transacionar com a empresa através do contrato, sendo-lhe enviados os pintinhos de 1 dia entregues na propriedade do integrado. Dentro do prazo de em média quarenta e dois dias (a média para criação do frango), o produtor receberá os medicamentos e vacinas, a visita constante do veterinário responsável pela assistência técnica, bem como o recebimento regular de ração, todos fornecidos por exigências contratuais da empresa, e ele ofertará a mão de obra para a criação do frango. A mão de obra é um insumo de difícil aquisição e de responsabilidade do produtor integrado. Em Mato Grosso, devido à crescente necessidade de pessoas habilitadas ao desenvolvimento da atividade de criação de frangos, o uso da tecnologia é imprescindível, pois garante o mínimo de mão de obra, sendo possível a contratação de um casal para os cuidados de um núcleo de quatro aviários $(\mathrm{f}=\mathrm{r})$. Em média, o frango consumirá $5 \mathrm{~kg}$ de ração durante este período. O custo do transporte do frango vivo (gaiolas) após a apanha/retirada da granja é de $\mathrm{R} \$ 28,12$ reais/tonelada ou o equivalente por quilômetro rodado de $\mathrm{R} \$$ 0,8034 dentro do municipio de Tangará da Serra, por exemplo (SIFRECA, 2009).

Frigoríficos e mercado - A distribuição dos produtos originários da indústria frigorífica, frango inteiro ou em pedaços, normalmente tem dois destinos: mercado interno e mercado externo. Para o mercado interno, são realizadas transações interestaduais através de agentes representantes que realizam a negociação para os estados de destino $(\mathrm{f}=\mathrm{r})$. $\mathrm{O}$ preço 
depende de negociação entre a indústria frigorífica e o cliente localizado, de acordo com informações da pesquisa, nos estados do Rio de Janeiro, Minas Gerais, Rondônia, Amazonas, Acre e Pará. Após a negociação de preços, um dos custos de transação passa a ser o frete a ser pago para o transporte do produto até o estado de destino.

Araújo e Martins (2003) realizaram estudo sobre o transporte de cargas frigoríficas na indústria avícola brasileira e constataram que o transporte somente se realiza se houver interesse por parte da empresa frigorífica, denominada de embarcador ou dono da carga. Evidenciaram ainda neste trabalho que as estruturas de governança vigentes são integração vertical, quando a empresa detém toda a frota de veículos para o transporte, terceirizada (regida por contratos formais ou informais), forma mista (parte contratual, parte verticalizada) e rara incidência de coordenação via mercado.

Os contratos para exportação, citados anteriormente, são esporádicos e realizados respeitando as exigências de cada país $(\mathrm{f}=0)$. Um desses clientes, os Emirados Árabes, exigem, por exemplo, que o frango tenha o certificado de abate Halau, o que significa um custo de transação a mais na comercialização, consequentemente, previsto em contrato. Em relação ao aspecto de comercialização, algumas indústrias frigoríficas fazem a distribuição através de departamentos internos, já outras terceirizam para empresas encarregadas do processo de agenciamento de contratos. A logística, que também envolve custos de transação, envolve a contratação de contêiner que é transportado até a planta industrial, carregado com os produtos destinados ao comércio exterior e transportado de volta ao porto de Santos, Paranaguá ou Jundiaí, para que seja enviado ao país de destino.

Produtor integrado e indústria - A determinação das estruturas de governança vigentes na cadeia produtiva da avicultura de corte sob a ótica dos produtores integrados é realizada a seguir, sendo necessária uma análise prévia dos fatores que influenciam na determinação das estruturas de governança emergentes. O principal fator é a especificidade 
de ativos que juntamente com a frequência das transações pode definir e influenciar a estrutura de governança vigente.

A estrutura de governança predominante nas relações com os produtores integrados em relação a todas as empresas integradoras é a forma híbrida, em que se verifica a existência de contratos de quaseintegração e baixa ocorrência de transações esporádicas. A governança de forma híbrida é incentivada pelos contratos de quaseintegração nas três empresas, "A", "C" e "B", o que desfavorece ações oportunistas entre indústrias processadoras e produtores, facilitando a transmissão de informações e o aumento da coordenação e eficiência.

Na integração de criação de frangos, os produtores recebem assistência técnica e também os insumos. O pagamento pelos serviços (engorda) é feito dez dias após a entrega dos lotes no frigorífico, por depósito em conta na instituição financeira credenciada.

A vantagem deste sistema, para os produtores, é a garantia de mercado para sua produção, e a transferência do risco (variação no preço dos grãos e falta de mercado comprador da carne avícola) para as agroindústrias. Mesmo assim, permanece certo nível de risco, advindo da necessidade de remunerar o avicultor em casos de retenção dos frangos nas granjas por um período maior de tempo, em épocas em que o mercado está desequilibrado (oferta superior à demanda). Nestes casos, o produtor integrado também tem problemas, pois acaba por receber menos, e seu trabalho passa ser maior, ou seja, sua rentabilidade cai.

A inserção dos contratos, como forma predominante de coordenação, ocorre ao mesmo tempo em que se eleva o processo de especialização e de escala das empresas. Porém, não existem elementos nos contratos analisados que evidenciam essa situação. As agroindústrias procuram elevar a escala de seus fornecedores (produtores de frangos) com a intenção de reduzir custos de produção e logística.

As análises dos contratos são descritas a seguir pelas especificidades dos ativos (locacional, físicos, dedicados), pela frequência e pela incerteza. 
Cleiton Franco, Sandra Cristina de Moura Bonjour, Benedito Dias Pereira

\& Talitha Soyara Zanini

A separação por estes tópicos foi feita para melhorar a compreensão dos resultados.

\subsection{Especificidades}

Especificidade Locacional - A especificidade locacional refere-se à necessidade de os produtores integrados se localizarem próximos às empresas processadoras. Nos contratos, não foram encontradas cláusulas relacionadas a esta especificidade.

Contudo, na avicultura, esta especificidade é importante pela existência do fator custo de transporte (que afeta diretamente a empresa processadora), pois a maioria das propriedades rurais possui estradas de acesso que não são pavimentadas e normalmente em má situação. Atinge também, de forma indireta, o produtor, pois se o custo do transporte for elevado, a empresa processadora não terá interesse em manter a integração, o que acarretará custos irrecuperáveis ao produtor, condizente com a especificidade de ativos físicos, descrita a seguir.

Especificidade de Ativos Físicos - Na avicultura, a manutenção e os equipamentos da granja são de responsabilidade do produtor rural, e os respectivos contratos vinculam-se à capacidade e condições destas instalações, bem como às licenças ambientais e sanitárias referentes à atividade. Estes itens são considerados ativos físicos, que não podem ser reempregados em outra atividade a não ser a avicultura. Todas as empresas citam esta especificidade em seus contratos.

Especificidade de Ativos Dedicados - A especificidade de ativos dedicados surge quando ocorrem investimentos por parte do fornecedor visando a atender à demanda de um cliente específico. Na avicultura, observa-se que os produtores rurais realizam estes investimentos para atender às necessidades de determinada empresa processadora.

Capacidade da granja, dimensões, equipamentos, localização, entre outros, são executados na intenção de atender as normas da empresa integradora. 
A especificidade de ativos é analisada sob três aspectos: ativos específicos, ativos intermediários e ativos reutilizáveis. Do ponto de vista do produtor, ativos específicos $(\mathrm{k}=\infty)$ são: a) Frangos de corte: são ativos específicos, pois não são passíveis de serem destinados a outras atividades que não o abate. Algumas categorias podem apresentar um grau menor de especificidade, como alguns machos selecionados e fêmeas, que são destinados à reprodução, no entanto, decorrido o tempo de reprodução, são destinados ao abate; b) Instalações e Equipamentos: As instalações como cortinas, exaustores, ventiladores, banheiros, portões sanitários, roupas para desinfecção e equipamentos como bebedouros e comedouros automáticos e balança são considerados ativos específicos, uma vez que são utilizados e dimensionados para o manejo de um lote, ou seja, de um número grande de aves; c) Pintinhos: também considerados ativos específicos, pois serão desenvolvidos em incubatórios e posteriormente enviados aos alojamentos para criação; d) Mão de obra: os recursos humanos utilizados na avicultura de corte constituem, talvez, um dos ativos com maior grau de especificidade. Além de ser um item de difícil contratação, são pessoas que vivem e exercem a atividade há muito tempo, sendo, muitas vezes, a única atividade que realmente conhecem. Isto faz com que seja difícil seu reaproveitamento em atividades agrícolas ou em outras atividades pecuárias, como criação de suínos, bovinos ou pecuária de leite. O produtor, no caso de ser também o proprietário, pode ser considerado um ativo específico, pois muitas vezes não deixa de exercer atividades, em lugar de outras mais rentáveis, por motivos de caráter pessoal, como tradição familiar e forte ligações com a propriedade; e) Fossa séptica: construídas nas propriedades para fins de eliminação de carcaças mortas, são ativos de difícil utilização em outras atividades e necessitam de investimentos para adaptação quando possível.

Quanto aos ativos intermediários $(\mathrm{k}=\mathrm{m})$ têm-se: $\mathrm{f})$ Terra: a terra pode ser considerada um ativo que na maioria das vezes pode ser utilizado com outra finalidade que não a avicultura de corte, apesar de existirem áreas que por possuírem características específicas são de difícil aproveitamento para atividade de agricultura ou reflorestamento. O que a torna um ativo intermediário e não reutilizável é o tempo e os 
Cleiton Franco, Sandra Cristina de Moura Bonjour, Benedito Dias Pereira

\& Talitha Soyara Zanini

investimentos necessários para que esteja apta a outra atividade; g) Silos, Caixas d'água: destinados à implantação, constituem ativos intermediários, pois podem ser reaproveitados de forma secundária para atividades agrícolas e pecuárias.

E finalmente, quanto aos ativos reutilizáveis $(\mathrm{k}=0)$ : h) Galpões/aviários: são ativos que podem ser aproveitados para atividades como confinamento de bovinos e suínos, com poucos investimentos para adaptação.

\subsection{Incerteza}

A incerteza refere-se à imprevisibilidade das atitudes posteriores dos agentes econômicos. Na produção de aves em Mato Grosso, esta incerteza é minimizada pela confiança dos produtores na indústria, além da existência de cláusulas bastante pormenorizadas nos contratos.

Tais cláusulas descrevem como acontece o fornecimento dos pintinhos de 1 dia, dos insumos, exigem a presença do produtor quando ocorre a vistoria ou visita e também quando da "apanha" dos frangos ao término do processo de engorda. Citam o compromisso de vender exclusivamente àquela empresa, a não criar outros rebanhos, como bovinos e suínos, e nem desenvolver atividade leiteira ou de criação de galinha caipira, entre tantos outros detalhes. Isto minimiza de forma bastante satisfatória a questão da incerteza nos contratos de avicultura.

Contudo, as agroindústrias reduzem as incertezas de fornecimento tanto qualitativo como quantitativo, mas assumem o risco com relação ao preço dos grãos (mesmo sendo bastante eficiente na compra e venda de grãos nas mesas de operação no mercado futuro) e nas variações do mercado comprador de carne avícola (mercado externo). Os produtores têm o risco de sua baixa remuneração. 


\subsection{Frequência}

A maioria dos contratos é feita por tempo indeterminado, desde que o produtor cumpra todas as normas e atinja o nível de produção estipulado pela empresa. Esta frequência de relacionamento é garantia para a empresa, que pode contar com um número certo de produtores e frangos para processamento, bem como para o produtor rural, que tem toda sua produção vendida. A frequência, no entanto, ocorre de 6 a 8 vezes no ano, a partir do momento em que se atinge a maturidade do frango (45 dias), há a necessidade de apanha.

Desta forma, o produtor mantém, na avicultura, uma opção de renda contínua durante o ano, não dependendo apenas da inconstância das safras de soja e milho.

\subsubsection{Análise dos contratos de integração em Mato Grosso sob a ótica da ECT}

$\mathrm{Na}$ integração de criação de frangos, os produtores recebem assistência técnica e insumos, como ração e medicamentos. O pagamento pelos serviços (engorda) é realizado no momento da entrega dos lotes ao frigorífico. A vantagem deste sistema, para os produtores, é a garantia de mercado para seus lotes de frango e a transferência do risco (variação no preço dos grãos e falta de mercado comprador da carne avícola) para as agroindústrias. Mesmo assim permanece certo nível de risco, advindo da necessidade de remunerar o avicultor em casos de retenção dos frangos nas granjas por um período maior de tempo, em épocas em que o mercado está desequilibrado (oferta superior à demanda). Nestes casos, o produtor integrado também tem problemas, pois acaba por receber menos e seu trabalho passa ser maior, ou seja, sua rentabilidade cai.

A inserção dos contratos como forma predominante de coordenação ocorre ao mesmo tempo em que se eleva o processo de especialização e de escala das empresas. Porém, não existem elementos nos contratos 
analisados que evidenciam essa situação. As agroindústrias procuram elevar a escala de seus fornecedores (produtores de frango) com a intenção de reduzir custos de produção e logística. A especialização do estabelecimento, para uma maior participação da avicultura na renda total, também não parece estar associada aos contratos, mas sim à tecnificação e aumento da escala de produção avícola, devido a uma disponibilidade limitada de capital, mão de obra e terra.

Tabela 2 - Participação das agroindústrias analisadas na cadeia produtiva da avicultura de corte em Mato Grosso a partir do número de aviários, produtores (contratos) e volume de abates/dia.

\begin{tabular}{c|c|c|c|c|c|c}
\hline Indústria & Aviários & $\%$ & $\begin{array}{r}\text { Produtores } \\
\text { (contratos) }\end{array}$ & $\%$ & Abates/dia & $\%$ \\
\hline A & 321 & $19 \%$ & 168 & $20 \%$ & 180.000 & $17 \%$ \\
B & 454 & $27 \%$ & 292 & $35 \%$ & 280.000 & $27 \%$ \\
C & 880 & $53 \%$ & 365 & $44 \%$ & 570.000 & $55 \%$ \\
\hline total & 1.655 & $100 \%$ & 825 & $100 \%$ & 1.030 .000 & $100 \%$ \\
\hline
\end{tabular}

Fonte: Dados da pesquisa (2008)

A Tabela 2 mostra o market share ou participação do mercado em Mato Grosso através do número de aviários, volume de abates diários e contratos, levando em consideração que todos os produtores possuem contratos de integração, ou seja, $100 \%$. A empresa que detém o maior número de aviários (alojamentos) (53\%), o maior número de produtores (44\%) e o maior volume de abates por dia (55\%) é a empresa " $\mathrm{C}$ ", situadas nos municípios de Campo Verde e Lucas do Rio Verde. Em seguida vem a empresa "B", com $35 \%$ dos contratos, situada nos municípios de Nova Mutum e Nova Marilândia e, por fim, a empresa "A", que possui $20 \%$ dos contratos de integração, situada nos municípios de Sorriso e Tangará da Serra. 


\subsubsection{Análise das cláusulas contratuais}

A partir da leitura dos documentos, foi estruturado e preenchido um banco de dados das cláusulas contratuais (Tabela 3) que permitiu classificar os temas abordados nos contratos por empresa. Além disso, permitiu a comparação entre os documentos em função de mudanças no tempo e entre agroindústrias ou diferentes sistemas de produção. Foram utilizados os contratos das três empresas residentes em Mato Grosso que possuem os contratos de integração.

Tabela 3 - Detalhamento dos contratos de integração para produção de frangos

\begin{tabular}{|c|c|c|c|}
\hline Item & Empresa A & Empresa B & Empresa C \\
\hline $\begin{array}{c}\text { Detalhamento dos pintinhos } \\
\text { na entrega }\end{array}$ & $\begin{array}{c}\text { em ótimas condições, de boa } \\
\text { linhagem }\end{array}$ & $\begin{array}{c}\text { em ótimas condições, de boa } \\
\text { linhagem }\end{array}$ & $\begin{array}{c}\text { em ótimas condições, de boa } \\
\text { linhagem }\end{array}$ \\
\hline $\begin{array}{l}\text { Quantidade fornecida } \\
\text { é dependente }\end{array}$ & $\begin{array}{l}\text { Das instalações, do período de } \\
\text { terminação, da necessidade da } \\
\text { empresa. }\end{array}$ & $\begin{array}{l}\text { Das instalações, do período de } \\
\text { terminação, da necessidade da } \\
\text { empresa. }\end{array}$ & $\begin{array}{l}\text { Das instalações, do período de } \\
\text { terminação, da necessidade da } \\
\text { empresa. }\end{array}$ \\
\hline $\begin{array}{l}\text { Prazo para entrega de novo } \\
\text { lote pela empresa integradora }\end{array}$ & Até 30 dias após a retirada. & Até 30 dias após a retirada. & Até 30 dias após a retirada. \\
\hline $\begin{array}{l}\text { Fornecimento de insumos (ração, } \\
\text { vacinas, medicamentos, } \\
\text { desinfetantes) }\end{array}$ & Sim. & Sim. & Sim. \\
\hline Preço do frango entregue & $\begin{array}{c}\text { Fixado de acordo com peso, } \\
\text { conversão alimentar, idade. Revisto } \\
\text { e alterado periodicamente. Varia } \\
\text { entre } 0,30 \text { e R } \$ 0,33\end{array}$ & $\begin{array}{c}\text { Fixado de acordo com peso, } \\
\text { conversão alimentar, idade. Revisto } \\
\text { e alterado periodicamente. Varia } \\
\text { entre } \mathrm{R} \$ 0,40 \text { a } \mathrm{R} \$ 0,50\end{array}$ & $\begin{array}{c}\text { Fixado de acordo com peso, } \\
\text { conversão alimentar, idade. Revisto } \\
\text { e alterado periodicamente. Varia } \\
\text { entre } \mathrm{R} \$ 0,33 \text { a } \mathrm{R} \$ 0,41\end{array}$ \\
\hline Prazo de vigência do Contrato & $\begin{array}{l}\text { em princípio indeterminado, porém } \\
\text { renovável de acordo com o prazo de } \\
\text { financiamento, em média, } 10 \text { anos. }\end{array}$ & $\begin{array}{l}\text { em princípio indeterminado, porém } \\
\text { renovável de acordo com o prazo de } \\
\text { financiamento, em média, } 10 \text { anos. }\end{array}$ & $\begin{array}{l}\text { em princípio indeterminado, porém } \\
\text { renovável de acordo com o prazo de } \\
\text { financiamento, em média, } 10 \text { anos. }\end{array}$ \\
\hline $\begin{array}{c}\text { Detalhamento dos frangos } \\
\text { para retirada }\end{array}$ & $\begin{array}{c}3,2 \mathrm{~kg} \text { para macho e } 2,7 \mathrm{~kg} \text { para } \\
\text { fềmea ou conforme necessidade da } \\
\text { empresa, podendo ser do tipo griller, } \\
35 \text { dias, tipo exportação. }\end{array}$ & $\begin{array}{c}2,3 \mathrm{~kg} \text { para macho e } 1,7 \mathrm{~kg} \text { para } \\
\text { fềmea ou conforme necessidade da } \\
\text { empresa, podendo ser do tipo griller, } \\
35 \text { dias, tipo exportação. }\end{array}$ & $\begin{array}{c}2,3 \mathrm{~kg} \text { para macho e } 1,7 \mathrm{~kg} \text { para } \\
\text { fêmea ou conforme necessidade da } \\
\text { empresa, podendo ser do tipo griller, } \\
35 \text { dias, tipo exportação. }\end{array}$ \\
\hline Responsabilidade das instalações & Integrado. & Integrado. & Integrado. \\
\hline Licença Ambiental e Sanitária & Integrado. & Integrado. & Integrado. \\
\hline
\end{tabular}

Fonte: Dados da pesquisa (2008). 
Cleiton Franco, Sandra Cristina de Moura Bonjour, Benedito Dias Pereira \& Talitha Soyara Zanini

Cláusulas sobre Obrigaçães das Partes e Volumes de Produção - Os contratos definem como obrigações das agroindústrias fornecer pintinhos de 1 dia, ração, medicamentos e outros insumos, prestar serviços de assistência técnica e de transporte. As obrigações do avicultor são seguir as orientações técnicas da agroindústria, fornecer mão de obra familiar ou contratada (inclusive encargos, tributos e responsabilidades decorrentes do seu emprego), prover instalações e equipamentos, água e energia, realizar manutenção e reformas necessárias e manter a trafegabilidade nas vias de acesso aos aviários. Além disso, deve se responsabilizar pelo tratamento, manuseio, uso, transporte, fossa séptica para aves mortas, devendo para tanto atender à legislação ambiental. Quase todos os contratos definem volume de produção e capacidade de alojamento.

Cláusulas sobre Remuneração - Os contratos de compra e venda têm em geral uma apresentação explícita da forma como se dará a remuneração do produtor de frangos, sobretudo através de tabelas de preços e prazos anexas aos contratos. Definem o preço a ser pago pelo frango com base na fórmula de eficiência, que leva em consideração o número de frangos por lote, descontadas as mortes e as deficiências das linhagens, levando também em consideração a conversão alimentar.

O principal incentivo (indexador aplicado sobre o preço de referência) é dado em função da conversão alimentar obtida pelo avicultor no lote entregue para o abate. Isso indica que o objetivo perseguido pelas agroindústrias é reduzir as despesas com alimentação, principal elemento no custo de produção (cerca de $70 \%$ ). Na maioria das vezes, é considerado o desempenho relativo, ou seja, a conversão alimentar obtida é comparada com a média dos demais lotes entregues nos últimos 30 ou 60 dias, implicando concorrência entre os avicultores. Apesar de não fazer parte da fórmula de remuneração, a mortalidade dos frangos também deve ser considerada, pois interfere no cálculo da conversão alimentar. O mesmo se pode dizer quanto ao rendimento do animal vivo em volume de carcaça. No entanto, já que esta conversão depende essencialmente da genética empregada, há pouco a ser feito por parte do produtor. 
Além deste incentivo, há um conjunto de especificações técnicas e gerenciais que, quando adotadas pelo avicultor, dão direito a uma bonificação que acrescenta até $25 \%$ à remuneração final. As especificações técnicas e gerenciais que dão direito a uma bonificação são monitoradas pela assistência técnica ou pela gerência das agroindústrias.

Cláusulas sobre Especificações Técnicas - A principal especificação técnica, presente em todos os contratos analisados, ocorre através de cláusulas voltadas à padronização dos animais para o abate, tais como definições de faixas de peso, limites de idade, períodos de retirada e prazo limite de povoamento entre os lotes (entre 21 e 30 dias). Destacase que não há uniformidade nestes parâmetros entre os contratos, tampouco entre as agroindústrias. Predominam as preocupações com o estágio de abate e processamento, como é o caso dos resíduos de medicamentos nos alimentos e a pesagem de animais com ração não absorvida (não transformada em carne). São poucos os contratos que têm cláusulas para definir padrões para as instalações, o carregamento de animais e o alojamento ou carregamento. Quase todos remetem esses temas à orientação técnica e às decisões do avicultor. É importante destacar que nenhum dos contratos analisados define especificações técnicas voltadas para o meio ambiente.

Cláusula sobre Monitoramento e Informações - O principal instrumento de monitoramento e transmissão de informações é a assistência técnica, prevista na maioria dos contratos, e amparada pela cláusula que estabelece livre e permanente acesso da agroindústria às instalações. Além disso, tendo em vista a constante preocupação com a sanidade dos rebanhos, todos os contratos preveem que o avicultor deve comunicar imediatamente qualquer anormalidade na sanidade e na mortalidade dos animais. Também frequente entre os contratos são as cláusulas sobre identificação e registros, tais como o acompanhamento dos lotes de frangos através de fichas de desempenho. 
Cleiton Franco, Sandra Cristina de Moura Bonjour, Benedito Dias Pereira

\& Talitha Soyara Zanini

Cláusulas sobre Prazos, Exclusividade, Garantias e Penalidades As cláusulas que estabelecem exclusividade de compra, venda e fornecimento de pintinhos, ração e demais insumos aparecem em quase todos os contratos. Em conjunto com as cláusulas de volume, permitem melhor coordenação da quantidade produzida. Além disso, são formas de garantir qualidade, uniformidade e rastreabilidade dos animais. Esta cláusula também abre a possibilidade para a regulação do contrato em função das condições de mercado. As garantias formais são definidas por um conjunto de instrumentos, no caso da agroindústria que fornece pintinhos e insumos (através de entrega). Por sua vez, o avicultor tem a garantia de venda, mas poucos contratos garantem o rendimento do avicultor através de um piso para a remuneração ou indenização por problemas sanitários. Os contratos têm prazo indeterminado de vigência ou cláusulas que preveem a possibilidade de renovação automática. Todos definem condicionantes e prazos de aviso prévio para a rescisão contratual, geralmente associada ao não cumprimento de cláusulas, desacordo com a legislação ambiental e sanitária e baixo desempenho. A maioria também prevê a possibilidade de aplicação de multas sobre algum indicador de valor ou volume da transação. Poucos abrem a possibilidade de revisão e ajustes periódicos. Todos os contratos preveem ainda a remuneração com até dez dias após a entrega do lote, por depósito em conta na instituição financeira onde foi realizada a atividade de financiamento.

Outras penalidades aparecem em mais detalhes no contrato com a empresa " $C$ ". A rescisão contratual envolvendo a empresa " $C$ " estipula para perdas e danos em caso de rescisão multa de $10 \%$ calculada sobre o somatório da renda obtida pelo integrado nos últimos seis meses, devidamente corrigidos pelo IGP-M da FGV. As situações que levam à rescisão contratual pelo produtor em relação à empresa integradora são as seguintes: 
a) não fornecimento de rações, vacinas, medicamentos, assistência técnica;

b) decretação de falência da empresa; e

c) inadimplemento de qualquer cláusula contratual.

Por outro lado, as situações que levam à rescisão contratual pela empresa em relação ao produtor são as seguintes:

a) lotes inferiores a $65 \%$ da produção e resultados inferiores à média prevista nos lotes abatidos;

b) aplicação pelo integrado de qualquer medicamento, ração não determinada pela empresa;

c) desvio de ração para outros plantéis como bovinos ou suínos;

d) Deixar de reter a posse do imóvel e das instalações;

e) Descumprir normas de biossegurança; e

f) Falecimento do integrado.

Nas empresas "A" e "B", as situações que levam à rescisão contratual são praticamente as mesmas, com exceção de que nestas duas empresas, caso haja insolvência do integrado ou falência, a empresa assume as instalações do integrado e se compromete a pagar o financiamento em seu lugar, percebendo para si os resultados que seriam do integrado.

\subsection{Integração vertical ou contratos de longo prazo?}

A análise do contrato empreendida até aqui permite afirmar que os elementos que foram se incorporando ao contrato contribuem para a redução dos custos conjuntos de produção e de transação, o que confirma, 
Cleiton Franco, Sandra Cristina de Moura Bonjour, Benedito Dias Pereira \& Talitha Soyara Zanini

em parte, a hipótese central da ECT. Em outras palavras, as modificações verificadas na estrutura de governança que governa a transação entre avicultores e indústrias de processamento foram respostas eficientes ao crescimento da especificidade decorrente de ativos dedicados, conforme preveria a proposição de Coase.

A integração vertical para frente, por parte dos avicultores, apesar de possível, necessariamente implica a coordenação de vários produtores a fim de que a produção de frango seja suficiente para atender à escala mínima do processo industrial. Se os custos de coordenação entre os avicultores não são elevados, há condições de integrar-se verticalmente para frente. Essa seria uma estratégia, a exemplo da indústria, de melhora do resultado de desacordo ou, mais provavelmente, de rejeição do papel de fornecedor de insumos para a agroindústria. Como há diversos avicultores com elevados custos de coordenação, há assimetrias entre indústrias e avicultores na estratégia de integração vertical.

Havendo o que barganhar (quaserrenda gerada por ativos específicos), a indústria tem incentivos para se integrar verticalmente e, assim, apropriar-se de uma maior porção da quaserrenda. Os avicultores com baixos custos de coordenação apresentam uma restrição de participação maior que os demais avicultores, cuja coordenação é custosa. Consequentemente, é possível que o preço frango - elemento que delimita quanto cada parte se apropria do excedente - possa ser inferior à restrição de participação desses avicultores com baixos custos de coordenação. Nesse caso, esse pequeno grupo de avicultores veria a integração vertical para frente como uma estratégia mais interessante que o fornecimento de insumos para a indústria. Assim, é possível se verificar uma integração vertical por parte dos avicultores, desde que seus custos de coordenação não sejam significativamente altos.

Apesar de haver integração entre avicultores e indústria processadora, situação de barganha poderá ser verificada na redução de estabelecimento de produtores (granjas) e aumento de aves alojadas. Os avicultores que apresentam grande número de aviários, como no caso de Lucas do Rio 
Verde, poderão realizar, caso não se sintam remunerados de forma a cobrir seus custos de produção, a barganha por preços melhores, como já ocorre no município de Nova Mutum. Em relação a matrizeiros, incubatórios e indústria de ração, a necessidade de integração vertical passa a ser, do ponto de vista estratégico, condição fundamental para garantir matéria-prima ao produtor integrado, evitando situações de flutuações de preços, impostas pelo mercado de fornecimento de matériaprima. No entanto, apesar de se integrar verticalmente para a fabricação de ração, a aquisição de insumos (soja e milho) ainda é fator de relações via mercado, pois nesta situação instrumentos de governo, como a Conab, garantem o a oferta de milho para as indústrias.

\section{Considerações finais}

A fusão da empresas Sadia e Perdigão formando a atual BRfoods não modificou o processo de contratos de integração em vigência no Mato Grosso. Em termos de produção, houve a permanência das características contratuais adotadas inicialmente na produção de frangos.

Por meio das análises realizadas, pôde-se concluir que, em termos de ambiente institucional e teoria dos custos de transação, a adoção de contratos leva à formação de estruturas de governança semelhantes nas três empresas estudadas e produtores entrevistados. Ou seja, foram observadas em Mato Grosso, estruturas de governança híbridas, com a presença de contratos formais na relação com produtores e na negociação com contratos de frete e comercialização do produto final. Entretanto, nas demais transações analisadas, como negociação de grãos e linhagens, foram observadas governanças através de mercado spot. Finalmente, quanto a matrizeiros, incubatórios e fábrica de ração, observa-se integração vertical.

A governança bilateral ficou evidenciada na relação entre produtores integrados e indústria frigorífica, pois seria resultado da existência de maior especificidade de ativos e maior frequência da transação, gerando 
relação de confiança entre as partes, que reduziria a possibilidade de litígio.

As transações realizadas em ambientes com elevado grau de incerteza não demandam necessariamente a integração vertical ou o mercado spot como formas de governança entre os agentes. Como observado, a dependência bilateral pode permitir governança híbrida, pois esta estimula os agentes a buscar adaptações a novas situações. A relação de dependência simétrica entre as partes poder levar à redução de oportunismo e à maior facilidade de adaptação a mudanças (tais como alterações nos preços, por exemplo).

Os contratos de integração podem ser considerados de média especificidade de ativos, com transações frequentes e reduzida incerteza. A especificidade dos ativos foi considerada média porque há necessidade de alguns equipamentos específicos, como investimentos na construção de granjas. Porém, a mão de obra no estado apresenta fortes problemas relativos à qualidade.

A frequência é considerada recorrente, devido aos investimentos realizados pelos produtores rurais (nas granjas e equipamentos), bem como pela empresa (na realização de planejamento de produção, roteiros de entrega de pintinhos e coleta de frangos, entre outros).

A incerteza é quase nula, tanto para as empresas quanto para os produtores. As empresas fornecem as rações, insumos e medicamentos, realizam apoio técnico às criações, podendo desta forma controlar a qualidade da carne e, se necessário, alterar os padrões. Os produtores rurais não precisam recorrer ao mercado para procurar compradores, pois no sistema de integração, eles têm conhecimento de datas e valores para receber pelo lote de frangos.

Os contratos analisados podem ser considerados quase completos, pois fazem menção a diversas circunstâncias que podem ocorrer, detalham as obrigações da empresa e do produtor integrado e são de fácil leitura e compreensão. 


\section{Referências}

ANUALPEC. Anuário da Pecuária Brasileira. São Paulo: Instituto FNP, 2011.

ARAÚJO, M. P; MARTINS, R. S. Transporte de Cargas Frigorificadas na Indústria Avícola: Evidências para uma Interpretação à Luz da Teoria dos Custos de Transação. IV Congresso Internacional de Economia e Gestão de Redes Agroalimentares. 29 a 31 de Outubro de 2003. FEA/ USP - Campus Ribeirão Preto.

BARROS, A. J. da S.; LEHFELD, N. A. de S. Fundamentos de metodologia científica: um guia para a iniciação científica. São Paulo: Makron Books, 2000. 122 p.

COASE, R. H. (1937). "The Nature of the Firm." Economica 4(November): 386-405.

FARINA, E. M. M. Q.; AZEVEDO, P. F.; SAES, M. S. M. Competitividade: mercado, Estado e Organização. São Paulo: Singular, 1997. $286 \mathrm{p}$

FARINA, E. M. M. Q.; ZYLBERSZTAJN, Décio. Competitividade no Agribusiness Brasileiro. Estudo Elaborado para o IPEA. Realização: PENSA/FIA/FEA/USP. São Paulo, Julho 1998.

FARINA, E. M. M. Q. Competitividade e coordenação de sistemas agroindustriais: um ensaio conceitual. Revista Gestão \& Produção. v.6, n.3, p.147-161, dez. 1999.

FIANI, R. A teoria dos custos de transação. In: KUPFER, D., HASENCLEVER, L. Economia Industrial. Rio de Janeiro: Campus, 2002. p. 276-306.

JOSKOW, P. L. Vertical integration and long term contracts: the case of coal-burning electric generating plants. Journal of Law, Economics, and Organization, 1, p. 33-80, 1985. 
Cleiton Franco, Sandra Cristina de Moura Bonjour, Benedito Dias Pereira

\& Talitha Soyara Zanini

MARCONI, M. de A.; LAKATOS, E.M. Técnicas de pesquisa: planejamento e execução de pesquisas, amostragens e técnicas de pesquisas, elaboração, análise e interpretação de dados. 4. ed. São Paulo: Atlas, 1999. $260 \mathrm{p}$.

NETO, Gabril Jorge. O espetáculo dos números do frango permanece em cartaz. in: ANUALPEC - Anuário da pecuária brasileira. São Paulo: Instituto FNP, 2011

NORTH, D. Custos de transação, instituições e desempenho econômico. Rio de Janeiro: Instituto Liberal, 1994. 38 p.

WILLIAMSON, O. Transaction-cost economics: the governance of contractual relations. Journal of Law and Economics, Chicago, v. 22, n. 2, p. 233-261, Oct. 1979.

. The modern corporation: origins, evolution, and attributes. Journal of Economic Literature, Stanford, v. 19, n. 4, p. 1537-1568, Dec. 1981

. The economic institutions of capitalism. New York: Free Press, $1985.450 \mathrm{p}$.

.The theory of the firm as governance structure: from choice of contract. Journal of Economic Perspectives, v. 16, n 3, p. 171 195, 2002 .

ZYLBERSZTAJN, D. Papel dos contratos na coordenação agroindustrial: um olhar além dos mercados. Aula Magna de abertura do XLIII Congresso Brasileiro de Economia e Sociologia Rural, Ribeirão Preto-SP, 2005.

ZYLBERSZTAJN, D.; SZTAJN, R. Direito e economia: análise econômica do direito e das organizações. Rio de Janeiro: Elsevier, 2005. $315 \mathrm{p}$. 
REVISTA DE ECONOMIA E AGRONEGÓCIO, VOL.9, $N^{\circ} 2$ 